\title{
Volver a Hayden White: algunas
}

reflexiones $^{*}$

\section{Back to Hayden White: Some \\ Thoughts}

\author{
Guillermo ZermeÑo \\ El Colegio de México \\ México
}

Correo:gmoz@colmex.mx

DOI 10.48102/hyg.vi55.329

\section{ABSTRACT}

This essay is, in essence, about the theoretical transformation of historiography. It deals with the changes that have occurred since 1960 in the self-understanding of academic history. When his Metahistory book appeared in 1973, the historiography medium was, indeed, not prepared to receive it, as his discussion was transferred mainly to the field of literary theory and criticism. Only after its translation into other languages in 1990, his work began to be discussed and taken seriously by historians. In particular, his discussion focused on knowing whether or not White accepted that the discourse of historians, in addition to its literary form, was able to refer to the past, as it had been postulated since the origins of scientific-academic history in the XIX century. Rather, this paper contends that White's main interest in his criticism of the historiographic establishment is meant to reveal the unity that underlies the classical oppositions upon which the identity of historiography was constituted; between history and literature, history and philosophy, his-

* Quiero agradecer en primer lugar a Perla Chinchilla, por su invitación, insistencia y paciencia, para navegar por los mares tempestuosos whiteanos. $\mathrm{Mi}$ gratitud se extiende a Norma Durán, organizadora ejemplar del Coloquio de Verano del 2019 dedicado a la obra de White. Buena parte de estas reflexiones están en deuda con las discusiones y comentarios abiertos por ella y con las conversaciones y las dudas compartidas, ya desde hace algunos años, con José Rabasa, Fernando Betancourt, Ricardo Nava y Alfonso Mendiola. 
tory and science, fiction and reality, theory and empirics, and so on. In particular, we try to observe two points in which White argues in favor of this intersection: between philosophy and history, on the one hand, and between history and literature, on the other. One of the consequences of this "de-concealment" is to show that modern historiography (a discourse that "simulates" linking the past, the absent, with the present) is a fundamentally metahistorical activity. That is why we will stop to examine the content of the conceptual form, "metahistory", to unveil what the historian produces when writing history. Thus, the question will be to focus attention on some "details", by observing their relevance in the understanding of temporality assisted by two discursive strategies: literary and historiographic. So, in order to "understand" White, it is necessary to place his reflections, not the context of enemy poles, but in an intermediate place (between the extremes); as a preamble to the design of a transdisciplinary space (neither exclusively historiographic nor exclusively literary, nor exclusively historical nor exclusively philosophical), and thus to be able to imagine a plausible reconceptualization of historiography after the crisis of nineteenth-century historicism. There is talk then of "reconsidering" to go back to White in order to gauge one of the thinkable possibilities for the future of historiography.

Key words: Hayden White, Theory of History, Historiography.

\section{Resumen}

Este ensayo trata básicamente de la transformación teórica de la historiografía. Versa sobre los cambios ocurridos a partir de I960 en la autocomprensión de la historia académica sobre sí misma. $\mathrm{Al}$ aparecer el libro de Hayden White, Metahistory, en I973, puede decirse que el medio de la historiografía no estaba preparado para recibirlo. Su discusión se traspasó sobre todo al campo de la teoría y crítica literarias. Sólo a partir de su traducción a otros idiomas, hacia I990, su obra comenzó a discutirse y a ser tomada en serio por los historiadores. En particular su discusión se concentró en saber si White aceptaba o no que el discurso de los historiadores, además de su forma literaria, era capaz de referir el pasado, tal como se había postulado desde los orígenes de la historia científico-académica en el siglo XIX.

Más bien, en este escrito se intenta sostener que el interés mayor de White en su crítica al establishment historiográfico se dirige a poner de manifiesto la unidad que subyace a las oposiciones clásicas sobre las 
que se constituyó la identidad de la historiografía: entre historia y literatura, historia y filosofía, historia y ciencia, ficción y realidad, teoría y empiria, etcétera. En particular se intenta observar dos puntos en los que White argumenta a favor de dicha intersección: entre filosofía e historia, por un lado, y entre historia y literatura, por el otro. Una de las consecuencias de este "des-ocultamiento" consiste en mostrar que la historiografía moderna (un discurso que "simula" unir el pasado, lo ausente, con lo actual, lo presente) es una actividad fundamentalmente metahistórica. Por eso nos detendremos en examinar el contenido de la forma conceptual "metahistoria" para develar lo que el historiador produce cuando escribe historia. Siendo así, la cuestión consistirá en centrar la atención en algunos "detalles" para observar su relevancia en la comprensión de la temporalidad asistida por dos estrategias discursivas: la literaria y la historiográfica.

De manera que para "entender" a White hace falta situar sus reflexiones, no en uno de los polos enemistados, sino en un lugar intermedio (entre los extremos); como un preámbulo para el diseño de un espacio transdisciplinario (ni sólo historiográfico ni literario, ni histórico ni filosófico), y así poder imaginar una plausible reconceptualización de la historiografía tras la crisis del historicismo decimonónico. Se habla entonces de "regresar" a White para calibrar una de las posibilidades pensables para el futuro de la historiografía.

Palabras clave: Hayden White, teoría de la historia, historiografía.

Artículo recibido: $18 / 02 / 2020$

Artículo aceptado: $17 / 03 / 2020$

A José Rabasa

La ironia es la muerte de la metafisica

E. M. Cioran

I

W unca es mal momento, menos ahora, para regresar a los cláuna época en el campo de la reflexión sobre la naturaleza del dis- 
curso histórico y la teoría de la historia; sobre la historiografía entendida como una forma discursiva hecha para ser leída, enseńada y aprendida. Se trata de una forma particular de poner y dejar por escrito un conjunto de situaciones que alguna vez sucedieron, de relaciones establecidas entre el pasado y lo que va ocurriendo en un presente siempre en movimiento hacia el futuro.

Entre los historiadores y académicos de la historia White fue uno de los primeros que realizó un estudio a profundidad sobre esta clase de discursos producidos durante el siglo XIx. ${ }^{1}$ Se dedicó a mostrar que este género literario especializado en explicar y narrar las cosas ocurridas en el pasado contenía en su estructura profunda, no perceptible a simple vista, un fondo figurativo o tropológico. Una cuestión que para el sentido común de la historiografía del siglo xx no era fácilmente reconocible debido a un sentido o expectativas de "realidad" desconectadas de las argucias de la retórica concebida como un arte del engaño, que había que evitar a toda costa para llegar a consignar sólo la verdad pura del pasado. ${ }^{2} \mathrm{El}$ redescubrimiento del carácter simbólico o figurativo de toda escritura, histórica o literaria significó, por esa razón, un escándalo en el medio de los historiografía autocomprendida como "científica" y distinta de la literatura de ficción, o nutrida puramente de la imaginación o fantasía del escritor. Es el punto en el que White se expuso a un debate que parece no tener todavía una resolución unánime.

Sin embargo, podría argüirse que lo que White intentaba hacer era dotar al trabajo del historiador, no sin ironía, de un mayor sentido de realidad acerca del tipo de producto que fabricaba, de su forma y de sus función, una reflexión que no había dejado de hacerse en otros campos, como el del arte o el de la ciencia. ${ }^{3}$ De modo que la cuestión abierta por White, en principio tenía que

${ }^{1}$ Hayden White, Metahistoria. La imaginación histórica en la Europa del siglo XIX. ${ }^{2}$ Hans-Georg Gadamer, Verdad y método. Fundamentos de una hermenéutica filosófica, pp. I 19 y ss.

${ }^{3}$ Hayden White, "The Burden of History", pp. 27-50. 
ver menos con la pregunta acerca de si se puede o no conocer el pasado, y más con la forma como el historiador creía poder situarse frente a esa posibilidad, con consecuencias para el desarrollo de un estilo o forma específica de representar el pasado por escrito. En ese sentido, parecería que White, situado en la corriente de la teoría crítica, en su libro Metahistoria no hacía sino realizar un ejercicio de crítica de la ideología; aquel ejercicio intelectual surgido en el siglo xIX con el intento de desocultar, de desinhibir, una conciencia que ignora lo que se hace al momento de producir un objeto. Un tema, éste, el de la conciencia alienada, enajenada, que está en boga en los años en los que White estaba pensando la historia desde su misma práctica: el recurso sine que non a las diferentes formas de verbalizar las relaciones entre el pasado y el presente por medio del lenguaje. ${ }^{4}$ Así cierra su famoso ensayo:

En aras de parecer científica y objetiva, se ha reprimido y se ha negado a sí misma su propia y principal fuente de fuerza y renovación. Al volver a poner en contacto a la historiografía con sus fundamentos literarios no deberíamos estar poniéndonos en guardia contra las distorsiones meramente ideológicas; deberíamos estar en el camino de alcanzar esa "teoría" de la historia sin la que ésta no puede en absoluto pretender ser una "disciplina".

2

$\mathrm{Al}$ aparecer la obra de White es probable que no haya encontrado en primera instancia a sus "lectores ideales" entre los historiado-

\footnotetext{
${ }^{4}$ Hayden White, "The Historical Text as Literary Artifact".

${ }^{5}$ Hayden White, El texto histórico como artefacto literario, en la traducción de Veronica Tozzi, p. I 39. Téngase en cuenta que su primera versión fue publicado en un número dedicado a las relaciones entre Historia y Literatura en Historia y Grafía, 2, I994.
} 
res. Esto debido en buena parte a que la historiografía de esos años a nivel internacional, no sólo latinoamericano, pugnaba por asimilar sus procedimientos a las teorías y métodos de las ciencias sociales como una forma de obtener reconocimiento como una "ciencia"; es decir, como una actividad ocupada no nada más en describir sino en explicar el pasado en función del presente del historiador. Se hablaba entonces, no obstante, de la historia como una ciencia en construcción referida sobre todo a la historia social, siendo uno de sus referentes sustantivos, además de Fernand Braudel, Eric Hobsbawm. ${ }^{6}$ Por eso, remitir a dicha "disciplina" al terreno del análisis del discurso podía parecer sospechoso: como un atentado a la pretensión de verdad del pasado tal cual. En ese sentido puede decirse que cuando apareció Metahistory en 1973 (Johns Hopkins University Press) el terreno no estaba preparado para su recepción. Nació prematuramente, antes de tiempo, fuera de lugar. Un libro precoz se puede decir. Esto explica en parte que su comentario y su discusión se dieran de preferencia en otros centros de estudios, y poco o nada en los dedicados al cultivo de la historiografía. Otro tanto se puede decir de La escritura de la historia de Michel de Certeau, original de I975, aunque con una recepción diferente en el medio de la historiografía francesa, no así en el de la norteamericana, igualmente recluido en uno de los centros de estudios literarios de la academia de dicho país. Pero es de advertir que los énfasis y el trato de uno y otro dado a la cuestión de la ficción y lo literario no son idénticos. Certeau estaba mucho más cerca de la crítica a la epistemología de la historia ventilada en el medio francés de Raymond Aron, Henri Marrou y Paul Veyne, enriquecida con insumos disciplinarios sociológicos, antropológicos y psicoanalíticos- más amplios, que el enfoque semiológico y literario adoptado por White. ${ }^{7}$

${ }^{6}$ Apuntes de dicha historia se pueden encontrar en José Antonio Piqueras, La era Hobsbawm en historia social.

${ }^{7}$ Las diferencias entre ambos no obstan para que, como señala Dosse, White manifestara su aprecio por el escrito "La operación historiográfica" y por la obra

22 / Guillermo Zermeño 
En todo caso, en de Certeau y en White existe la coincidencia de la crítica ideológica al modelo cientificista instaurado durante el siglo XIX. Coincidencia, por otro lado, que se puede rastrear asimismo en un autor anterior, menos conocido, como Emery Neff quien publicó en 1947 The Poetry of History. The Contribution of Literature and Literary Scholarship to the Writing of History since Voltaire (Columbia University), mencionado de paso por White en Metahistoria al referirse a la concepción de la historia de Carlyle. ${ }^{8}$ Si bien el trabajo de Neff se ubica más claramente (no había llegado el momento del estructuralismo) en el terreno de la historia de las ideas, no por eso pierde interés al dejar ver ya algo que estaba en el aire y hacía titubear a los historiadores del siglo XIX: la presencia de un fondo literario, sobre todo cuando se piensa en el proceso de traducir el pasado en el lenguaje de los contemporáneos. Más próximo a las preocupaciones y las reflexiones de White está la sugerente compilación de 1978 de Robert H. Canary y Henry Kozicki, The Writing of History. Literary Form and Historical Understanding (University of Wisconsin Press).

No obstante las dificultades y las resistencias ante los cuestionamientos y el enfoque analítico adoptado por White en Metahistory, para 1990 el libro ya iba en la séptima reimpresión. Un libro raro en el medio por su espíritu polémico sin tapujos. Por la complejidad de su planteamiento y por su ambición intelectual en cuanto al intento de esclarecer la naturaleza del discurso de la historia: al abarcar a la vez los hilos entretejidos de cuestiones epistemológicas, éticas, político-ideológicas y lingüísticas, sobre las que está montada su producción. Así que se puede aceptar también que, se hubiera leído o no, el texto se convirtió en relativamente poco tiempo en un "clásico", si bien pagando su costo: quedar sometido al mundo de los prejuicios de la crítica

historiográfica de de Certeau. François Dosse, Michel de Certeau, El caminante herido, pp. 4I6; 426.

${ }^{8}$ White, Metahistoria, op. cit., pp. I45-I 46. 
para lo bueno y para lo malo ("es un autor posmoderno"), sin requerir su lectura (bastante exigente por lo desacostumbrado y la amplitud de su radio de acción) y, mucho menos, su análisis o decodificación. Así, la mayoría de sus críticos lo situaron del lado de la crítica literaria y del "giro lingüístico", el cual no significaba sino un atentado de una disciplina en apariencia saludable.

Lo que correspondería a la crítica es examinar con cuidado los argumentos de White para esclarecer la función de lo literario en el discurso histórico. Y es que la crítica de Hayden White al establishment historiográfico se orienta fundamentalmente hacia una epistemología histórica que ignora el carácter textual de su producción. Esta desatención se tradujo en una concepción de la historia volcada hacia una narratología aséptica sustentada en la neutralidad aparente de un "método". Ahora bien, es verdad, como se ha apuntado, que White no es un caso único en reflexionar en esos años, y mucho más en años recientes, sobre el problema de las relaciones entre diferentes disciplinas afines como son la historia y la literatura, o la historia y la geografía, la historia y la filosofía, la historia y la ciencia, la historia y el arte, etcétera. ${ }^{9}$ La cuestión apunta no tanto a extrapolar a favor o en contra de uno de los polos de la ecuación, sino a descubrir y delinear los puntos donde se intersectan sin anularse la producción intelectual y la científica.

La traducción al español de Metahistoria. La imaginación histórica en la Europa del siglo XIX y en otros idiomas -en alemán en I99Iapareció en I992. Poco antes, en I987, en nuestra lengua se había publicado un breve ensayo en el que se hace mención del trabajo de White, El discurso histórico de Jorge Lozano. Un manual,

${ }^{9}$ Por ejemplo, John L. Gaddis, El paisaje de la historia. Cómo los historiadores representan el pasado.

24 / Guillermo Zermeño 
una síntesis comprensiva que marcaba, si se quiere, la entrada en la historiografía de la problemática inducida en los escritos de White relacionados con la historia, pero también con el campo de la cultura y su crítica. En contraposición implícita, ya que no hay referencia al trabajo de White, en aquellos años se publicó asimismo un manual bastante influyente en el que se reafirmaba la vocación eminentemente social, no discursiva, de la historia: el de Josep Fontana, Historia. Análisis del pasado y proyecto social (1982). Situado en el otro polo del espectro de la historiografía de aquellos años, reafirmaba en cierto modo la vocación filosófica o transformadora de la historia, una historia para la acción, para la cual lo discursivo significaba sólo un desvío, un distractor de la verdadera historia concebida como una actividad científica. Por eso es natural que en dicho libro se encuentre en su mayoría a la historiografía social neomarxista en boga en Gran Bretaña y a la New Left norteamericana de los años sesenta, y nula mención a la obra de White. Debido al peso que tenía en esos años la historia social, era hasta cierto punto comprensible que White fuera un perfecto desconocido hasta antes de la traducción de su obra a otras lenguas.

De manera que, tras el libro de Lozano y la precedente traducción del libro de de Certeau La escritura de la historia en I985, la publicación en español del libro de White en I 992 significó la invitación para aproximarse al problema de la historia visto desde una dimensión desatendida: desde la crítica del discurso y la literatura. El problema de la historia tenía que ver con la historia del problema, es decir, implicaba adoptar como observador una posición metahistórica, no necesariamente filosófica, para descubrir la presencia de la retórica figurativa en el ensamblaje y dramatización de los relatos históricos producidos durante el siglo xIX, casi sólo como pretexto para esclarecer una cuestión a la que se le daba nueva vida: la pregunta acerca de si la historia era una ciencia o un arte; acerca de la indagación sobre qué tan cerca o tan lejos estaba la historia de la circularidad de los relatos míticos; y todo 
esto sucedía en plena era de la ciencia como motor de una historia progresista. Frente al dilema de si la historia era una ciencia o un arte, White situó el punto crítico en cuestión del desfase temporal que había en la comprensión por los historiadores con respecto a la ciencia; se maniobraba todavía en la historiografía con nociones un tanto arcaicas o anacrónicas, tanto en relación con la noción de "arte" como de "ciencia". ${ }^{10}$

Por tratarse de un diagnóstico de la historiografía mexicana quisiera recordar aquí una conferencia impartida por Elías Trabulse (especialista en historia de la ciencia) en la Universidad Iberoamericana de la Campestre Churubusco después del temblor, en 1987. En el marco de un ciclo de conferencias organizado con motivo de la celebración del trigésimo aniversario de la creación del Departamento de Historia, la intervención de Trabulse estuvo inspirada de forma expresa en la lectura del trabajo de White, misma que causó gran revuelo en el medio de la historiografía nacional al llegar a la opinión pública a través del semanario Proceso ${ }^{11}$ Fue "memorable" al ofrecer una semblanza crítica sobre

${ }^{10}$ Peter Novick, Ese noble sueño. La objetividad y la historia profesional norteamericana, I, I76. En alusión a su ensayo El peso de la historia de 1966 y traducido al español en Nexos, núm. 53, mayo de i982, pp. 23-33.

${ }^{11}$ Federico Campbell, "Los historiadores ya no son los críticos del sistema: Elías Trabulse". "Nosotros los historiadores hemos estado enseñando en un lenguaje de mudos. Hemos abandonado el papel de críticos del Estado y del sistema. Al alejarnos de la hermenéutica, y abandonarnos a la pura actitud heurística, nos hemos convertido en una suma de personas o de instituciones, pero de ninguna manera en una conciencia". "Nadie se atreve a criticar la mitografía oficial. La crítica se acabó. Vivimos el triunfo de la mediatización”. "Así, pues, la desacralización del poder no ha estado en manos de los historiadores. Ha estado en manos de los literatos o de los historiadores metidos a periodistas. Ellos han abierto la crítica social, que nosotros no hemos hecho. A los historiadores se nos ha escapado dicha crítica”. La historia mexicana, continúa Trabulse, está en auge, "pero a pesar de ello los historiadores no somos la conciencia crítica de la nación. El tiempo de la ironía ya no está con nosotros. Las vocaciones se han vuelto profesiones. El ciclo histórico que empezó en I970 se cerró en I968, por obra de los que no son historiadores". En consecuencia, según Trabulse, "los literatos de este país son los que han asumido la crítica social, la crítica del Estado”.

\section{6 / Guillermo Zermeño}


el nacimiento y desarrollo de la historiografía profesional en México utilizando algunas de las nociones desarrolladas por White. Abolía entre otras la noción de "precursores" en la historiografía e incursionaba en la necesidad de reescribir la historia de la historia para reavivar a una disciplina conservadora que vivía de glorias pasadas.

Quisiera igualmente mencionar que, a la par de la traducción del libro de White, la Universidad Iberoamericana publicó en I99I un trabajo que trastocaba de modo radical la manera como las crónicas de la conquista habían sido utilizadas por la modernidad nacionalista: como meras fuentes de información etnográfica, sin reparar en el ensamblaje o formas de dramatización estructurantes del sentido específico relativo a la misma información. Se trata de la aparición del libro de Alfonso Mendiola elaborado con el instrumental alemán de la teoría de la recepción de las obras literarias e historiográficas, Bernal Díaz del Castillo: verdad romanesca y verdad historiográfica. Una lectura de las crónicas de la conquista innovadora al ser hecha desde la perspectiva no tanto de los hechos en sí, sino de los lectores, una forma de sacar a la historiografía de su ostracismo para regresarla a la historia y a la sociedad a través del análisis de sus prácticas de lectura y escritura. ${ }^{12}$ Era una manera como se estaba dando espacio para adentrarse en algunos de los cuestionamientos de White relacionados con un tipo de presupuestos cientificistas infundados, en particular con la cuestión acerca de la presencia de la "ficción" en la historiografía. Una noción precisada de clarificación, dada su ambigüedad semántica, ya que con facilidad se le podría confundir con el arte de fingir o del engaño, o, a secas, de la construcción surgida puramente de la mente fantasiosa de una persona.

\footnotetext{
${ }^{12}$ Guillermo Zermeño, "Traer la historia a la Historia”, pp. 67-69; Id.; "La historia verdadera: el punto de vista del lector", pp. I2-I 3.
} 
A propósito de un ensayo sobre Proust, Blas Matamoro nos recuerda también que, en sí, la escritura de la historia pertenece al orden de lo imaginario y de la memoria, pero también al del deseo. La tríada memoria, deseo e imaginación sería la base sobre la que se funda el orden de lo imaginario. Lo cual, como aclara J. M. Sánchez-Prieto siguiendo a Ricoeur, hace sentido si se establece asimismo la relación triangular entre lo "imaginario" (el campo propio de las representaciones) y la tríada presentista: un "presente pasado" como memoria, un "presente presente" como visión y un "presente futuro" como espera. ${ }^{13}$ Aunque el punto central, siguiendo a Kant, residiría en que todo acto de imaginación presupone la relación entre un objeto y su representación o imagen. De modo tal que el objeto (exterior) funciona como el referente de una imagen (interior) que tiene lugar en el presente de la percepción o visión.

En ese contexto, la diferencia que habría entre la historia y la literatura se sustentaría sólo en que la segunda puede prescindir supuestamente del objeto, es decir, del soporte o referente de la imaginación. Así, si la representación literaria carece de objeto, su espacio pertenecería al reino de la fantasía o imagen sin objeto, a diferencia de la historia, que no puede prescindir del objeto referenciable. Pero si se mira con más detenimiento, tanto la historia como la literatura comparten mucho más de lo que se ha llegado a pensar, ya que el objeto -aquello que se refiere o de lo que se habla- está asimismo ausente para ambos, en razón de que en los dos casos propiamente el objeto tiende a no ser contemporáneo o coespacial con la imagen. De aquí no se seguiría la negación de la existencia del pasado como el objeto de estudio de la historia. Se concluiría sin más que lo ya-no-existente (el recuerdo, por ejemplo) se transmite por medio de una imagen que por lo general -aunque no siempre- tiene la forma de escritura.

${ }^{13}$ Juan María Sánchez-Prieto, "El baúl de Lévi-Strauss", p. 253.

28 / Guillermo Zermeño 
Así se podría aceptar que esa forma-escritura contiene los tres elementos antes mencionados: el deseo que se presenta como anticipación; la memoria que se entiende como pretérito y la imaginación, si el objeto está ausente, que adquiere existencia al momento de nombrarlo. Así tampoco es fácil seguir manteniendo que la literatura tome sólo a la imagen pura, vacía, como su objeto, aunque, es verdad, puede darse el caso de la imagen-imagen, el sueño del psicoanálisis, como si se tratara de una representación incorpórea, y por tanto perteneciera al reino puro de la fantasía. Sería la excepción que confirma la regla: trátese de historia o de literatura, toda percepción o visión es siempre un acto creador o al menos rectificador de objetos. De manera que ambas convenciones o modos de trabajar el pasado se reencuentran de alguna forma en la "fabulación", o lo que White denomina como "imaginación histórica". Lo esencial radica en que siempre se imagina, se desea o se recuerda algo ausente; y que lo ausente -el recuerdo- se trae a la actualidad por medio de la imagen cargada tanto de deseo de futuro como de rememoración del pasado. ${ }^{14}$ Ahora bien, como veremos, esa forma-escritura tiene también una historia; ${ }^{15}$ una dimensión que, debido al peso del modelo formalista utilizado por White, pasa de largo, pero que resulta decisiva a la hora de historizar los mismos procesos destacados en su análsis tropológico.

5

Entonces, volver a White significa sobre todo retornar a la historiografía del siglo xIX para repensar críticamente la historiografía

\footnotetext{
${ }^{14}$ A partir de lo sugerido por Blas Matamoro, Por el camino de Proust, pp. 44-45. Esta reflexión está presente también en la contribución de Marco Aurelio Larios, "Espejo de dos rostros. Modernidad y postmodernidad en el tratamiento de la historia”, pp. I 30-I 3 I.

${ }^{15}$ Niklas Luhmann, "La forma escritura", pp. 3-2 I.
} 
desde el siglo Xx. Y sin duda una manera de clarificar el estado que guarda una disciplina es haciendo su historia. ${ }^{16}$ Pero ya en nuestro caso, ese regreso para observar algunas de las transformaciones de la historiografía en el siglo xx ya están hechas en el XxI. Si bien, habría que respetar la lógica argumentativa de White, de que la mera sucesión cronológica no es lo decisivo para dar cuenta y explicar las transformaciones en la concepción acerca de una forma o estructura discursiva como sería la historiografía. Este énfasis es tal porque White ante todo es un historiador que está repensando la historia desde el "momento estructural"17 dominante en los medios académicos durante la década de $1960 .^{18}$ Y ahí aparece, entre otros, su lectura y uso de otro clásico de la crítica literaria: Norbert Frye, Anatomía de la crítica (1977). Ese sesgo, es verdad, puede darle a su modelo analítico un toque que enfatiza lo estático sobre lo dinámico, lo arquetípico sobre lo histórico.

En su libro Metahistoria, White se aplica al análisis de algunos de los clásicos de la historiografía europea del siglo XIX, tanto filósofos (Herder, Hegel, Marx, Nietzsche, Croce) como historiadores propiamente dichos (Michelet, Ranke, Tocqueville, Burckhardt). En su análisis realiza un corte en el tiempo que va de la reacción "romántica" (Herder) a la Ilustración, del énfasis en el sentimiento a la razón, hasta el intento de Croce de convertir a la historia en una disciplina irónica, despegada de sus pretensiones de asimilarse a los procedimientos de las ciencias físico-matemáticas. El momento examinado por White se corresponde entonces

\footnotetext{
${ }^{16}$ Por ejemplo, Georg G. Iggers, Historiography in the Twentieth Century. From Scientific Objectivity to the Postmodern Challenge.

${ }^{17}$ Hayden White, "An Old Question Raised Again: Is Historiography Art or Science? (Response to Iggers)".

${ }^{18}$ Con lo que eso significa: un retorno a la figura de Saussure y su Curso de lingüistica general, publicado en I916. La lengua, no el lenguaje, es concebida como un todo, como un sistema, hecho de recursividad, repetición, y cambio, sincronía y diacronía. Véase, Jean-Claude Milner, El periplo estructural. Figuras y paradigma.
} 
con la emergencia de la historiografía científico-moderna, para mostrar que su compostura y articulación arrastra consigo un lastre del pasado, que fue reprimido y rechazado, el resabio de las viejas formas de la retórica clásica, que en la nueva historiografía se manifiesta como una forma estructural transhistórica. Es decir, que hace ver que no hay una diferencia sustancial entre las antiguas formas de contar la historia y las nuevas. Que lo que se encontraría en cuanto a la diferencia entre el discurso histórico y el mítico, el explicativo y el metafórico, entre lo "científico" y lo "estético", es sólo una cuestión de matices, de detalles. Trasladado dicho "corte" al examen y diagnóstico de la historiografía del siglo xx, del momento desde donde White realiza su incisión crítica de la historiografía académica ya consolidada, predomina en ese sentido un enfoque "estructuralista", formalista, en el que lo atemporal, lo ahistórico, priva sobre lo histórico. Esta afirmación vale en exclusiva desde una óptica surgida de una historia de la historiografía avalada por una semántica histórica, o análisis histórico del uso de las palabras y los conceptos.

No es tanto que White no tome en consideración la historia de la historiografía, desde Heródoto pasando por Gibbon hasta Burckhardt y Croce (y la recuperación de este último de lo que constituye la crítica del modelo cartesiano y desarrollo de una sematología o nueva ciencia de leer los signos antiguos ${ }^{19}$ ); sino que su análisis estructural del relato histórico se queda anclado en el siglo XIX sin dejarnos ver las transformaciones históricas operadas dentro de la misma "estructura" del relato histórico. En parte ese olvido de White se debe a que sus críticos se han centrado en el cuestionamiento de su énfasis dado a la cuestión de la tropología que supondría asimismo la imposibilidad de observar la construcción de los relatos históricos como discursos de verdad, o capaces de transmitir la realidad del pasado. Propiciada en parte por el mismo White al ubicarse dentro de la corriente "posmodernista",

${ }^{19}$ Jürgen Trabant, Neue Wissenschaft von alten Zeichen: Vicos Sematologie. 
sinónimo de relativismo, del todo se vale; es decir, de dar cabida a la posibilidad de la fabricación de fake histories o pseudohistorias, historias falseadas, sinónimo de historias en las que la imaginación poética es más fuerte y decisiva que el esfuerzo ascético de la razón para poner orden y dirección o "sentido" al caos propio de lo "real histórico", y las sucesivas polémicas y reacciones derivadas sin poder llegar un "final feliz". ${ }^{20}$

Por eso buena parte de las discusiones epistemológicos en torno a la obra de White tienden a centrarse en la cuestión del realismo en la historia, un tema que a su vez cuenta con una historia tan larga como la historia, ya que tiene que ver con el modo como las sociedades construyen su sentido de realidad, o lo que es lo mismo, su sentido de lo que es verdad y lo que no lo es. ${ }^{21} \mathrm{Y}$ en este aspecto parece que el historiador Hayden White de sus inicios "abandona" la historiografía para internarse más bien en el mundo polifacético de los estudios culturales, espacio transdisciplinario propicio para el ejercicio de la crítica política y estética. Por eso, mi impresión es que la obra de White quedó presa, enjaulada dentro de su propia imagen, perdiendo de vista la pregunta principal que sigue ocupando actualmente a las ciencias sociales y las humanidades: entender cómo las sociedades evolucionan, cómo anudan, a través de qué técnicas y artificios articulan las relaciones entre la temporalidad, el paso del tiempo, el sentido y sus formas de dar cuenta de la "historia" y la "cultura". ${ }^{22}$

\footnotetext{
${ }^{20}$ Novick, Ese noble sueño, II, op. cit., pp. 7 I 2-747.

${ }^{21}$ Sobre esta cuestión, Alfonso Mendiola ha podido profundizar en su libro Retórica, comunicación y realidad. La construcción retórica de las batallas en las crónicas de la conquista.

${ }^{22}$ Guillermo Zermeño, "Apuntes sobre algunos conceptos clave de la historia cultural".
} 
Entrecomillo la palabra "historia” debido a su ambigüedad semántica, ${ }^{23}$ como podría ser también el caso del término "filosofía"; un aspecto que tal vez para White no sea tan relevante, pero que tiene fuertes implicaciones cuando se trata de trasladar los lenguajes del presente, del historiador, para describir la cultura de otros pueblos, otras culturas, presentes o pasadas. ${ }^{24}$ Ya que se vislumbran en su concepción de la historia restos de una historia de las ideas que nos recuerda a Collingwood, quien anticipa, por otro lado, una reflexión importante sobre la historia como una ciencia sui generis, ${ }^{25}$ si bien no es que Collingwood ni White ignoren el peso que tienen las palabras y sus variaciones semánticas. ${ }^{26}$ Pero lo que ya no ven es que la "Idea" es también un vocablo, que es reflejo de la imaginación creativa de la mente humana y que funciona como una especie de a priori kantiano, o espacio en el que se prefigura lo que aparecerá en las reconfiguraciones operadas por el escritor de historias. El punto crítico reside en saber si dicho a priori está vacío de contenido, es una forma pura, o en sí mismo está ya preformado antes de conocer; es decir, que forma parte de la evolución y transformación operadas dentro de una cultura determinada. Así, se podría asumir que más que tratarse de un a priori vacío, eterno, estructural, propio de la naturaleza humana, está conformado también históricamente.

Tal sería en mi opinión la alternativa ofrecida por Gadamer, próxima a una cierta hermenéutica practicada por White, al in-

\footnotetext{
${ }^{23} \mathrm{Me}$ remito al estudio ya clásico de Reinhart Koselleck, historia/Historia. Pero también, en esa dirección, al esfuerzo a nivel iberoamericano recogido en mi ensayo "De la historia como un 'arte' a la historia como una 'ciencia".

${ }^{24}$ Cfr. El estudio ya clásico de François Hartog, El espejo de Heródoto. Ensayo sobre la representación del otro. Véase también, Neal Ascherson, Black Sea. The Birthplace of Civilisation and Barbarism, p. 27.

${ }^{25}$ Robin George Collingwood, "La filosofía de la historia de Croce" pp. 4I-62.

${ }^{26}$ R. G. Collingwood, Idea de la naturaleza, pp. 58-9; o Id., "Historia de la palabra 'arte"', pp. I 5-I6.
} 
tentar salir del atolladero o aporía kantiana de las formas puras de la intuición, ${ }^{27}$ y reformular dicho a prioria partir del examen de la noción de "prejuicio" (Vorurteil, préjuge), central durante el periodo de la Ilustración, como sinónimo de pensamiento infundado, mágico, supersticioso; todo lo cual hay que combatir y vencer para dar a luz al hombre nuevo dirigido por una razón pura o sin adjetivos. Los pre-juicios, en ese sentido, en vez de ser el obstáculo serían la condición de posibilidad de toda comprensión. ${ }^{28}$

En el marco de lo que se conoce como "crisis de la razón occidental", en la que están implicados tanto el descrédito de las filosofías de la historia como los universalismos del modelo neokantiano de pensar y escribir la historia, se entiende, no obstante, la cuestión apuntada por White: la necesidad de analizar la dimensión tropológica, soterrada, encubierta, no tematizada, en las narrativas "científicas" de la historia. En ese punto entreveo un enlace entre Gadamer y White: en el intento de ambos de de-velar, des-cubrir, una dimensión preconceptual en-cubierta, al momento de querer re-velar el mundo de las cosas del pasado a los lectores. Lo que White, en la jerga del estructuralismo, denomina "estructura profunda" subyacente a la capa más superficial de los discursos históricos modernos.

Sin embargo, formulado de esa manera se deja ver nada más una cara de la moneda: la conformación histórica de un tipo de pre-juicios que funciona como un tipo de a priori antes de toda experiencia. Queda por saber cómo operan dichos "prejuicios", no sólo como parte de una "imaginación histórica", de modo que sean observables y develados para otras épocas y otras culturas. $\mathrm{Y}$ es que, siguiendo a Gadamer y su principio de lingüisticidad no es la imaginación pura la que define su carácter, sino el lenguaje expresado o comunicado, con todo y su ambivalencia, sin

\footnotetext{
${ }^{27}$ Immanuel Kant, Contestación a la pregunta: ¿Qué es la Ilustración? (1784), pp. 7-I7.

${ }^{28}$ Gadamer, Verdad y método, op. cit., pp. 337-354.
} 
el cual el mundo referido no es observable. Es ahí donde me permitiría destacar, no en términos absolutos, el valor de la historia conceptual en vistas al esclarecimiento de la historicidad propia de conceptos como el de la historia y la historiografía y sus mediaciones lingüísticas. Una forma, hasta cierto punto, de mayor afinidad con quienes trabajan en el campo de la filología y los estudios literarios (pienso en Ricardo Piglia y Martin Kohan, por ejemplo). Quienes comparten con White su crítica al realismo ingenuo, propio de la novela (Balzac) y la historiografía de mediados del siglo xIx por igual, que deja ver a la historia y la literatura como hermanos gemelos, hijos de la misma madre.

Un ejemplo de este "deseo" de "verdad real", no ficticia, sin cortapisas, fundada, no obstante, todavía en la metáfora del "espejo" y reforzada por la aparición de la fotografía, se tiene en I8 55 para el caso de Perú. Víctor Samuel Rivera, en su estudio semántico sobre el concepto "historia", constata el criterio de identificación de la verdad en la historia con el hecho de haber estado presente ante los hechos narrados; la autoridad se funda en la figura del "testigo presencial". Así, en su Diccionario para el Pueblo Republicano, democrático, moral, político y filosófico de I855, Juan Espinosa lo estipula: "si la historia no es el espejo de la época a que se refiere, si no la retrata con la veracidad del daguerrotipo, en vez de ser historia es cuentón". ${ }^{29}$

Una de las implicaciones derivadas de esta aspiración (anticipación) tendrá que ver con el establecimiento de Tucídides como el historiador veraz frente a su contraparte, Heródoto, como el historiador mentiroso por ser demasiado crédulo ante lo que le cuentan. Oposición que Hartog se encargará más tarde de desactivar en su obra clásica sobre el "padre" de la historia occidental, armado de la lingüística del siglo xx, y abriendo una vía efectiva, "crítica", para reconceptualizar y repensar la historiografía de manera más compleja y refinada. No necesariamente "mejor" que

${ }^{29}$ Víctor Samuel Rivera, "Historia-Perú", p. 656. 
las anteriores, sino más apropiada a las complejidades de las nuevas situaciones de nuestro presente; dejando ver a su vez de qué modo el establishment historiográfico puede seguir siendo, salvo excepciones, un lugar "ideal" para someter a la prueba del tiempo, como en un laboratorio, los modelos acunáados por la tradición, el pasado. Repensar la historia en el sentido de ofrecer salidas a las aporías intelectuales no resueltas llegadas del pasado al presente.

De manera que podríamos dar por sentado en el análisis de White el carácter discursivo, lingüístico de la historia en términos genéricos. Si bien White habla de dos corrientes en pugna, una superficial y otra profunda, una si se quiere más densa y otra más ligera. Como dos corrientes marítimas que se topan en sentido contrario, pero siempre en pugna y en tensión. Ni pura tropología ni puro logocentrismo. El problema es saber cómo una ciencia del detalle, de lo particular, como es la historia, puede concebirse como una actividad científica o artística; o su contrario: científica y estética, filosófica e historiográfica, cronológica y narrativa a la vez. Cómo acabar de clarificar su objeto específico de estudio a la vez que diseñar las estrategias narrativas ajustadas a dicho objetivo, sin dar lugar a la sospecha de convertir dichas narraciones en pura ideología o en la pura fantasía de una mente rica en imaginación, terreno en el que parece todo valerse, tal como los detractores al "giro lingüístico" acusan a sus defensores sin matiz alguno, al contraponer textualidad con "realidad". En cualquiera de sus formas se trata de un malentendido que, a pesar de los esfuerzos de White por esquivarlo, aún sigue vigente.

\section{7}

Como se ha dicho arriba, el diagnóstico crítico analítico realizado por White parte de un corpus documental englobado en lo que se conoce como el nacimiento de la historia en sentido moderno. Fundamentalmente se trata de la instauración del modelo insti- 
tucional que tendió a profesionalizar las dos vías de acceso a la historia: la histórica y la filosófica. En torno al establecimiento del modelo del seminario alemán se crearon dos lugares enfrentados: el conjetural o filosófico y su contrario, el no especulativo o una disciplina de trabajo apegada, respetuosa, de las fuentes de información del pasado y del presente concebidas como "testimonios", que hacen ver ya el trabajo del historiador como análogo al del juez de un tribunal que despeja las pruebas para descubrir el móvil de lo acontecido. Cada una de las partes, la filosófica y la histórica, con su propia especificidad en cuanto a lo esperado obtener: lo específico, lo particular, de lo histórico, enfrentado a la filosofía, ciencia de lo general. Sin embargo, para White las diferencias entre ambos procedimientos no son sustantivas. Son de matices tomando en cuenta la estructura profunda que, en medio de sus diferencias, les da unidad. Mezclar estas dos formas puede parecer osado analíticamente al minusvalorar sus especificidades discursivas y genéricas ya que cada una de las producciones obedece a espacios circunscritos de manera institucional y a un tipo de lectores diferenciados. Utilizar esa mezcla para establecer el diagnóstico crítico acerca de la cientificidad de la historia puede resultar, en ese sentido, cuestionable. Quizá no en otro sentido: en cuanto que ya tiene que ver menos con la historia de la historiografía y de la ciencia del siglo xIx, y mucho más con la forma como llegan ambas modalidades al siglo xx.

En ese contexto se ha planteado que las reflexiones críticas de White son impensables si no se toma en cuenta la crisis del historicismo; en particular, la filosofía de la historia, misma (se podría sostener) que es asimismo compartida abierta o tácitamente por el grueso de la historiografía practicada durante el siglo xx. White no es proclive a la historia conceptual en buena parte por situar su planteamiento crítico del lado de la metáfora y la tropología en oposición al conceptual. Pero su análisis sí se enfoca a la intelección y descripción del surgimiento de un tipo de memoria social característico de Occidente basada en lo histórico. Incluye tam- 
bién el distanciamiento crítico irónico realizado por Nietzsche hecho desde los márgenes del establishment universitario alemán. Una irrupción que hace aflorar un problema no pensado ni por unos ni por otros, aunque sí bosquejado por la crítica de los románticos al racionalismo kantiano, recogido por Collingwood y prolongado de manera parcial por White al realizar el elogio de la imaginación histórica en crítica a los elementos fosilizados de la escuela historicista alemana, al perder de vista el sentido de lo histórico, de su propia formación y convertir el paradigma de la historia en una metafísica disfrazada de empirismo; en un dogma fundado en una metodologismo estéril, reacio a la teoría, a observarse a sí mismo en su forma de observar, a pensarse a partir de su propia práctica, y no meramente desde el mundo de las "ideas", es decir, más allá de toda filosofía especulativa de la historia.

Ahora bien, insistir en situar la producción del trabajo de White en el contexto de la crisis de la historia historicista en su doble modalidad, filosófica y empiricista, es una invitación a detenerse y reflexionar en torno a dos de los equívocos que siguen acompañando la recepción de White: las relaciones entre filosofía e historia y las de historia y literatura.

Dichos equívocos suelen darse ya en lo que puede significar una misma palabra utilizada, pronunciada o traducida en diferentes idiomas. El equívoco inicial, por ejemplo con la palabra "historia" es la forma como ésta llegó del original griego al latino, en la que ya se observa una alteración del sentido original. Lo mismo se podría decir de la palabra "filosofía", término que se sigue utilizando todavía para situar el trabajo de White como historiador y como crítico cultural: es el trabajo de filósofo de la historia. En parte con razón por hacer de la crítica cultural un campo aplicable a diferentes prácticas relacionadas con la cultura. Aquí la filosofía se entiende como una ciencia de lo general. Y en ese sentido muchas de las reflexiones tienen que ver con el campo de la lingüística, en forma análoga a la importancia que ésta podría tener para otras ciencias. Pero en un sentido más restringido, 
el trabajo de White tiene que ver menos con la filosofía y más con el diseńo de una teoría sobre la práctica de la escritura de la historia y la pregunta sobre sus condiciones de posibilidad y sus alcances. Y aquí es verdad que su clarificación pasa por el terreno de la historia intelectual y de las instituciones, de las reglas de su operación y delimitación. En particular con el deslinde de la historia con la literatura, o de la diferencia que podría haber entre la retórica y los modos ficcionales de la prosa literaria, por un lado, y la retórica y los modos ficcionales de la historiografía, por el otro.

Visto desde la historiografía, por tanto, se puede ubicar a White más como un teórico que como un filósofo de la historia, aun cuando por razones idiomáticas puede él mismo dar lugar a que se le considere como lo segundo, y menos como historiador. La distinción entre lo uno y lo otro se puede apreciar mejor si se considera que propiamente la noción "filosofía de la historia" surge en el siglo XVIII y se disemina en el XIX, como una entidad distinta de la historiografía. En cambio, la noción de la teoría de la historia, como lo muestran un sinnúmero de títulos, pertenece al siglo xx. Surge con el avance y la radicalización del pensamiento científico relacionado con la cuestión de la identificación de sus límites, lo cual lleva a la reevaluación y reconceptualización de las relaciones entre ciencias de la naturaleza y ciencias histórico-culturales.

Ahora bien, el libro Metahistoria apareció cuando todavía podía haber expectativas con respecto al quehacer historiográfico de corte "filosófico-históricas", sin que pudiera identificarse con exactitud de dónde podría venir dicho mandato. Así, podría haber estudiosos interesados en la historia para descubrir una regularidad, una orientación lógico explicativa suficiente como prevenir y proyectar el futuro, sobre la base de que, a través de un estudio riguroso del pasado, podían identificarse las reglas o leyes que gobernaban el transcurrir de la historia. Es claro que esta expectativa o deseo de saber no se inventó en el siglo xx: era parte de un legado anterior derivado de la Ilustración, de otro 
siglo. En particular Kant fue uno de los filósofos que planteó la posibilidad de cumplir dicha expectativa con respecto al estudio de la historia: la de esperar que en forma análoga a las ciencias de la naturaleza se pudiera llegar a descubrir en la historia humana un tipo de leyes que acaso gobernaban el acontecer histórico; y, en la medida en que pudieran conocerse sistemáticamente, "científicamente", poder orientarse con más conocimiento de causa por la vía del perfeccionamiento y del progreso.

De hecho, la primera vez que apareció el sintagma "filosofía de la historia" fue en una carta escrita por Voltaire el 4 de marzo de I765 desde Ferney a Damilaville, en la que se menciona como autor de la noción al abate Bazin en un libro aparecido en Amsterdam en 1765 que, como editor, lo firma un sobrino del abate, y está dedicado a Catalina la Grande de Rusia. El libro contiene una sinopsis de la historia universal, empezando con consideraciones geológicas, de las razas humanas y las formas tempranas de la religión. Le sigue una historia cultural de la China antigua y del Medio Oriente a través de los judíos, desde la época de Abraham hasta la Edad Media. El periodo temprano bíblico está suprimido; en ese sentido la transmisión del legado judío está abordada críticamente. Se trata de un manual "filosófico" en la medida en que seculariza la historia de la salvación. "Filosóficas" son, por consiguiente, en el ensayo sobre las costumbres y el espíritu de las naciones de Voltaire, las caracterizaciones de pueblos y épocas, acompañadas de abstracciones y máximas generalizadoras.

Aunque en sí la expresión "filosofía de la historia" que priva a la fecha se debe a Johann Gottfried Herder (I744-I 803), quien publicó en 1774 La filosofía de la historia para la educación de la humanidad. Ahí Herder toma a la antigüedad de la humanidad como el modelo del desarrollo histórico, semejante al crecimiento de un árbol y a la experiencia de un viaje, y al transcurrir progresivo hacia un futuro de mayor virtud, moralidad y felicidad. Con esto aparece la historia como sistema, que exige un tratamiento "filosófico". Establecido el marco general se trata simple 
y llanamente de poner por escrito la historia de la humanidad en su desarrollo y formación, en su movimiento constante. Hegel complementó esta proposición al afirmar que las cosas devienen "reales" a partir del momento en que son aprehendidas de modo conceptual. De no ser así, entonces habría "arte" entre los griegos antiguos, "historia" en el Antiguo testamento, "Estado" ya entre los romanos, aun cuando en dichas culturas y lenguajes no se encuentren los conceptos correspondientes. Y lo mismo se aplicaría a la noción de "Filosofía de la historia", ${ }^{30}$ formalizada también en el escrito posterior de Herder, Ideas para una filosofía de la historia de la humanidad, de $1803 .{ }^{31}$ Aquí es interesante anotar una cuestión crítica señalada por Herder al evaluar el modelo apropiado para juzgar y ordenar la secuencia de una historia progresista de la humanidad. En particular su crítica se enfoca a la manera como el historiador del arte antiguo, J. J. Winckelmann (I7 I7-I768), valora las obras egipcias tomando como modelo de su crítica el arte griego. ${ }^{32}$ Con ello, argumenta Herder, sólo se obtiene un negativo de la imagen de Egipto, sin poder por ello "representárselas en su naturaleza, en su propio modo de ser”, además de mostrar que "en cada una de las fases de su obra maestra se transparenta su evidente parcialidad, y su vista torcida". ${ }^{33}$

Lo interesante es que en ese siglo de la historia y del progreso se formalizaron institucionalmente disociadas las dos vías de acceso a la Historia: la filosófica o especulativa o conjetural, como apuntó Niebhur, y la empírica, la hegeliana y la rankeana. ${ }^{34} \mathrm{El}$

${ }^{30}$ J. G. Herder, Filosofía de la historia para la educación de la humanidad (I774), pp. 25-40; Alexander Demandt, Philosophie der Geschichte, pp. 336-337.

${ }^{31}$ Johann Gottfried Herder (1744-1803).

${ }^{32}$ Johann J. Winckelmann, Reflexiones sobre la imitación de las obras griegas en la pintura y la escultura.

${ }^{33}$ Herder, Filosofía de la historia, op. cit., p. 37. La crítica se refiere a los trabajos de Johann Joachim Winckelmann, Histoire de L'Art dans L'Antiquité (I764).

${ }^{34}$ Esta doble trayectoria puede rastrearse igualmente para el caso europeo y para el de los nuevos estados de la América hispánica surgidos de sus procesos de emancipación del árbol de la monarquía católica. 
ejercicio analítico que realiza White en retrospectiva es todavía más interesante al preguntarse por la unidad que subyace a dicha diferencia institucionalizada. Así, a partir de su instrumental analítico tomado prestado de la teoría literaria White incluye en un mismo corpus tanto a los filósofos de la historia, materialistas o idealistas, como a los historiadores sin más. Y para hacerlos observables y comparables recurre a la fabricación de la noción de metahistoria, no en el sentido filosófico o especulativo, sino observacional. Una noción teórica en el sentido de un lugar desde donde el observador otea el conjunto para poder distinguir unas piezas de otras, un tipo de árboles de otros. De esa manera ingeniosa White logra mostrar la unidad que subyace a la operación de unos y de otros, con el riesgo de no dejarse apreciar diferencias significativas que podría haber en cuanto al tipo de prosa utilizada. Sin duda uno de los logros en su propuesta es haber abierto la compuerta para identificar la creación de un tercer espacio, para pensar el problema de la historia más allá de las exigencias propias de cada disciplina institucionalizada.

Ahora bien, White va más allá de Nietzsche en cuanto a realizar el análisis de las relaciones entre las formas o estructuras narrativas de la historia y sus contenidos, y en consecuencia sobre los posibles efectos o derivaciones pragmáticas que pueden tener dichas composiciones discursivas en los lectores potenciales. En ese sentido, uno de sus logros consistió en revelar la presencia de la retórica en la escritura de la historia moderna y mostrar que el establecimiento de la verdad en la historia está atravesado también por el filtro de las mediaciones lingüísticas. Forma parte de la evolución de las formas y soportes de comunicación de los que se sirve el ser humano para transmitir sus experiencias y conservar su memoria. En el caso de la historiografía occidental, perteneciente al ámbito de una producción sustentada fundamentalmente en la escritura impresa.

Por eso no sin razón se puede ubicar la obra deconstructiva de White (en el sentido de crítica de la ideología o metafísica sub-

42 / Guillermo Zermeño 
yacente a la autocomprensión cientificista de la historia) como la antimetafísica o antifilosofía de otros analistas como Arthur C. Danto, en lo que se conoce no sin equívocos como "giro lingüístico" ${ }^{35}$ En algunos casos, llevado al extremo de ubicarlo con sentido peyorativo en el campo del posmodernismo como amenaza para la defensa de las virtudes epistémicas del paradigma "científico" de la historiografía. ${ }^{36}$ Desde otro lugar, sin pasar por los filtros críticos de White, están las reflexiones de Lutz Niethammer. El término "posthistoria" no hace sino describir el escepticismo o desencantamiento respecto a las esperanzas depositadas en la estructura narrativa de los discursos filosóficos de la historia fabricados durante el siglo xIx. Discursos problemáticos si se intenta disponer de una teoría apropiada para la comprensión de la reconfiguración en marcha de la sociedad y de la historia mundial. Y apuesta por una alternativa crítica racional y emocionalmente fundada para responder a la cuestión sobre el tipo de servicios que los historiadores pueden ofrecer a los todavía interesados en la historia. ${ }^{37}$

Después de White, entonces, no habría que confundir "filosofía" con "teoría" de la historia, lo cual significa incluir en el campo de la reflexión historiográfica el problema de la narración, sobre todo con el de composición a fin de acercarse de la mejor forma posible al mundo histórico vivido en realidad, no sólo pensado. Ahí entran en cuestión la reflexión sobre si es posible o no narrar historias de manera no teleológica, finalista, o "historicista”. Así como tampoco son lo mismo los procesos de "ficcionalización" en la historia que los que ocurren en el campo de la literatura. Cuestión que despertó el interés de Roger Chartier, entre otros, para debatir con la postura representada por White en torno al problema de las relaciones entre representación y referencialidad

\footnotetext{
${ }^{35}$ Elisabeth A. Clark, History, Theory, Text. Historians and the Linguistic Turn. ${ }^{36}$ Por ejemplo, no sin interés está el trabajo de Ernst Breisach, Sobre el futuro de la historia. El desafio posmodernista y sus consecuencias.

${ }^{37}$ Lutz Niethammer, Posthistoire. Has History Come to an End?, p. I 49.
} 
en la historiografía. Una cuestión crucial que sigue abierta ${ }^{38}$ en cuanto a acabar de clarificar por medio del diálogo crítico, si es eso posible, las implicaciones teóricas y epistemológicas abiertas por la obra de White.

Este ensayo ha tratado entonces sobre la transformación teórica de la historiografía, sobre el paso de la filosofía a la teoría de la historia a partir del caso de Hayden White. Versa sobre los cambios ocurridos a partir de 1960 en el modo como la historiografía se ha comprendida a sí misma. Cuando apareció el libro Metahistory de Hayden White en I973, difícilmente el medio de la historiografía estaba preparado para recibirlo. Eso explica su recepción y maduración hasta cierto punto tardía, ya que en su discusión tomaron parte más integrantes de la teoría literaria que de la historia. Algunas de las dificultades de su recepción se deben a su espíritu polémico, pero, sobre todo, a la complejidad de su planteamiento y ambición intelectual en vistas a esclarecer la naturaleza del discurso de la historia, desde el punto de vista epistemológico, ético, político-ideológico y lingüístico. Si bien la crítica de Hayden White al establishment historiográfico se orienta sobre todo hacia una epistemología histórica que ignora el carácter textual de su producción. Esta desatención se tradujo en una concepción de la historia volcada en una narratología aséptica sustentada en la neutralidad aparente de un "método".

White también es uno de los representantes de un conjunto mayor que intentan identificar los puntos en los que se inter-

${ }^{38}$ Roger Chartier, "Cuatro preguntas a Hayden White". Véase también la respuesta de White, "Respuesta a las cuatro preguntas del profesor Chartier". Chartier prosiguió sus reflexiones críticas en su balance historiográfico, "La historia hoy en día: dudas, desafíos, propuestas", en el que sin duda tiene especial relevancia una cierta defensa de la historia frente al desafío y las provocaciones intelectuales de White.

44 / Guillermo Zermeño 
sectan diversas disciplinas. En particular está a la búsqueda de descubrir la unidad perdida que subyace por un lado a la relación entre filosofía e historia, y por el otro, a la que existe entre historia y literatura. Una de las consecuencias de esta búsqueda consiste en mostrar que la historiografía moderna (un discurso que "simula" unir el pasado, lo que ya no está, con el presente) es una actividad fundamentalmente de corte metahistórico. Otra de las consecuencias de dicho descubrimiento tiene que ver con la reflexión en torno al carácter ficcional del discurso de la historia, como distinto asimismo del carácter ficcional de la literatura.

A la sombra del legado de White se podría concluir que "metahistóricamente" no existe una diferencia sustancial entre el discurso histórico y el discurso literario, aunque sí podría haberlo en cuestión de detalles, de énfasis. Es un asunto que habría que investigar con mayor detenimiento para calibrar su relevancia o irrelevancia. Mientras a nivel superficial el texto histórico puede diferenciarse del texto literario, por debajo habría una estructura profunda, de carácter poético, tropológico, propia del lenguaje figurado. ${ }^{39}$ Tal sería el elemento "metahistórico", sin el cual no son pensables en la historiografía los estilos en el modo de trazar las conexiones explicativas entre el pasado y el presente.

De forma que se podría sostener a fin de cuentas que la reflexión historiográfica de White busca situarse en un lugar intermedio (entre los extremos); intenta abrir un espacio transdisciplinario (ni puramente historiográfico, ni puramente literario, ni puramente histórico ni puramente filosófico), para pensar y reconceptualizar la historia. En ese sentido se puede hablar de regreso al White de aquellos años para calibrar algunas de las posibilidades teóricas para el futuro de la historiografía, pero también para el conocimiento del accionar de la historia y de otras disciplinas afines. Puntos de intersección, no de exclusión, puntos de

\footnotetext{
${ }^{39}$ Alfonso Mendiola, "Hayden White: la lógica figurativa en el discurso histórico moderno".
} 
diálogo, no de reduccionismos, puntos de inflexión y de invitación a pensar la historia y su producción de manera más compleja.

Después de "volver a White" se puede dar por sentado, primero, que es un pensador-historiador que forma parte de una corriente más amplia de reflexión sobre la historia hecha desde la historiografía misma. Esto hace todavía más necesario el desarrollo de una critica historiográfica solvente y consistente que permita que la historia termine por clarificar su particularidad y sobre todo de fundamentarla frente a otros saberes afines; frente a los cuales ha tendido a situarse como un saber subsidiario sin acabar de determinar su objeto de estudio. Visto a la distancia se trató de un esfuerzo por familiarizar a la historia de algo que por diferentes razones a investigar había dejado de ser familiar. Para regresar siempre que sea necesario, por fortuna nos quedan las huellas de White, de sus escritos, que cubren una buena parte del curso de la historia y de la teoría de la historiografía de las últimas décadas. 厚

\section{BiBLIOGRAFÍA}

Ascherson, Neal. Black Sea. The Birthplace of Civilisation and Barbarism, Londres, Vintage, I 996.

Breisach, Ernst. Sobre el futuro de la historia. El desafio posmodernista y sus consecuencias, Valencia, Puv, 2009.

Canary, Robert H. y Henry Kozicki. The Writing of History. Literary Form and Historical Understanding, Madison, University of Wisconsin Press, I978.

Campbell, Federico. "Los historiadores ya no son los críticos del sistema: Elías Trabulse”, Proceso, I 2 de diciembre, I987. [En línea].

Collingwood, R. G. "Historia de la palabra 'arte', en Los principios del arte, México, FCE, I960, pp. I 5-I6.

- Idea de la naturaleza, México, FCE, 1950.

Collingwood, Robin George. "La filosofía de la historia de Croce" (I92I), en Ensayos sobre la filosofía de la historia, Barcelona, Barral Editores, I970, pp. 4I-62.

46 / Guillermo Zermeño 
Chartier, Roger. "Cuatro preguntas a Hayden White", Historia y Grafía 3, I994, Pp. 23I-246.

. "La historia hoy en día: dudas, desafíos, propuestas", en Ignacio Olábarri y Francisco Javier Caspistegui (dirs.), La "nueva" historia cultural: la influencia del postestructuralismo y el auge de la interdisciplinariedad, Madrid, Editorial Complutense, 1996, pp. 19-33.

Clark, Elisabeth A. History, Theory, Text. Historians and the Linguistic Turn, Cambridge, Harvard University Press, 2004.

Demandt, Alexander. Philosophie der Geschichte, Köln/Weimer/Wien, Böhlau, 20I I.

Dosse, François. Michel de Certeau. El caminante herido, México, Uia, 2003. Fontana, Josep. Historia. Análisis del pasado y proyecto social, Barcelona, Crítica, I982.

Frye, Norbert. Anatomía de la crítica, Caracas, Monte Ávila, I 977 [1957].

Gadamer, Hans-Georg. Verdad y método. Fundamentos de una hermenéutica filosófica, $3^{\text {a }}$ ed., Salamanca, Ediciones Sígueme, I 988.

Gaddis, John L. El paisaje de la historia. Cómo los historiadores representan el pasado, tr. Marco Aurelio Galmarini Rodríguez, Barcelona, Anagrama, 2006.

Iggers, Georg G. Historiography in the Twentieth Century. From Scientific Objectivity to the Postmodern Challenge, Middletown, ст, Wesleyan University Press, I997.

Hartog, François. El espejo de Heródoto. Ensayo sobre la representación del otro, tr. Daniel Zadunaisky, México, FCE, 2003.

Herder, J. G. Filosofía de la historia para la educación de la humanidad (I774), tr. Elsa Tabernig, Buenos Aires, Ediciones Espuela de Plata, 2007.

Johann Gotffried Herder (1744-1803), Antología bilingüe compilada por Manuel Velázquez Mejía, México, Toluca, Universidad Autónoma del Estado de México, 2000.

Kant, Immanuel. Contestación a la pregunta: ¿Qué es la Ilustración? (I784), Madrid, Taurus, 20I2, pp. 7-17.

Koselleck, Reinhart. historia/Historia, tr. Antonio Gómez Ramos, Madrid, Trotta, 2004 .

Larios, Marco Aurelio. "Espejo de dos rostros. Modernidad y postmodernidad en el tratamiento de la historia", en Karl Kohut (ed.), La invención del pasado. La novela histórica en el marco de la posmodernidad, Frankfurt/Madrid, Vervuert, 1997, pp. I30-136.

Lozano, Jorge. El discurso histórico, Madrid, Alianza 1987. 
Luhmann, Niklas. "La forma escritura", tr. Guillermo Zermeño, Estudios Sociológicos, El Colegio de México, xx:58, 2002, pp. 3-2 I.

Matamoro, Blas. Por el camino de Proust, Barcelona, Editorial Anthropos, I988.

Mendiola Alfonso. Bernal Díaz del Castillo: verdad romanesca y verdad historiográfica, México, Uia, I991.

—. "Hayden White: la lógica figurativa en el discurso histórico moderno", Historia y Grafía I 2, I999, pp. 2 19-246.

- Retórica, comunicación y realidad. La construcción retórica de las batallas en las crónicas de la conquista, México, Uia, 2003.

Milner, Jean-Claude. El periplo estrucural. Figuras y paradigma, Buenos Aires, Amorrortu, 2003.

Neff, Emery. The Poetry of History. The Contribution of Literature and Literary Scholarship to the Writing of History since Voltaire, Nueva York, Columbia University, I947.

Niethammer, Lutz. Posthistoire. Has History Come to an End?, Londres, Verso, 1992.

Novick, Peter. Ese noble sueño. La objetividad y la historia profesional norteamericana, t. I y t. II, tr. Gertrudis Payás e Isabel Vericat, México, Instituto Mora, I997.

Piqueras, José Antonio. La era Hobsbawm en historia social, México, El Colegio de México, 20 I 6.

Rivera, Víctor Samuel. "Historia-Perú", en Javier Fernández Sebastián (dir)., Diccionario politico y social del mundo iberoamericano, [Iberconceptos I], Madrid, Fundación Carolina/Centro de Estudios Políticos y Constitucionales, 2009.

Sánchez-Prieto, Juan María. "El baúl de Lévi-Strauss", en La "nueva” historia cultural: la influencia del postestructuralismo y el auge de la interdisciplinariedad, en Ignacio Olábarri y Francisco Javier Caspistegui (dirs.), Madrid, Editorial Complutense, I996.

Trabant, Jürgen. Neue Wissenschaft von alten Zeichen: Vicos Sematologie, Frankfurt, Suhrkamp, I994.

White, Hayden. "An Old Question Raised Again: Is Historiography Art or Science? (Response to Iggers)", Rethinking History 4:3, 2000, pp. 39I-406. White, Hayden. El texto histórico como artefacto literario, intr. y tr. Verónica Tozzi, Barcelona, Paidos, 2003.

Grafia 2, I994, pp. 9-34.

48 / Guillermo Zermeño 
Metahistoria. La imaginación histórica en la Europa del siglo XIX, tr. Stella Mastrangelo, México, FCE, I 992.

- "Respuesta a las cuatro preguntas del profesor Chartier", Historia y Grafia 4, 1995, pp. 317-329.

_. "The Burden of History" (1966), en Tropics of Discourse. Essays in Cultural Criticism, Baltimore, The Johns Hopkins University Press, I978, pp. 27-50.

—. "The Historical Text as Literary Artifact" (1974), en Tropics of Discourse. Essays in Cultural Criticism, Baltimore, The Johns Hopkins University Press, 1978.

Winckelmann, Johann Joachim. Histoire de L'Art dans L'Antiquité ( I 764), tr. Dominique Tassel, París, Le livre de Poche, 2005.

- Reflexiones sobre la imitación de las obras griegas en la pintura y la escultura, tr., intr. y notas de Salvador Mas, México, FCE, 2008.

. "Apuntes sobre algunos conceptos clave de la historia cultural", en Norma Durán R. A. (coord.), Estudios culturales. Voces, representaciones $y$ discursos, México, UAM-A, 2017, pp. 23-56.

- "De la historia como un 'arte' a la historia como una 'ciencia", en Historias conceptuales, México, El Colegio de México, 2017, pp. 67I 24 .

. "La historia verdadera: el punto de vista del lector", La Jornada Semanal, nueva época, núm. I05, I6 de junio de I991, pp. I2-I3. - "Traer la historia a la Historia" (sobre el libro de Alfonso Mendiola), Umbral XXI, México, Uia, 7, I991, pp. 67-69. 